\title{
In vivo delivery of pPERDBY to BALB/c mice by LacVax DNA-I and comparison of elicited immune response with conventional immunization methods
}

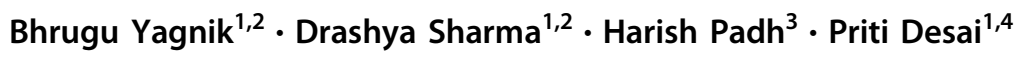

Received: 10 February 2018 / Revised: 29 May 2018 / Accepted: 30 May 2018 / Published online: 14 August 2018

(c) Springer Nature Limited 2018

\begin{abstract}
The non-invasive food grade Lactococcus lactis (L. lactis) represents a safe and attractive alternative to invasive pathogens for the delivery of plasmid DNA at mucosal sites. We have earlier shown the DNA delivery potential of $\mathrm{r}-L$. lactis harboring DNA vaccine reporter plasmid; pPERDBY in vitro. In the present work, we examined in vivo delivery potential of food grade non-invasive r-L. lactis::pPERDBY (LacVax DNA-I) in BALB/c mice. Moreover, using EGFP as a model antigen, we also characterized and compared the immune response elicited by LacVax ${ }^{\circ}$ DNA-I with other conventional vaccination approaches using protein and naked DNA immunization. The presence of antigen-specific serum IgG and fecal secretory IgA (sIgA) antibodies demonstrated in vivo DNA delivery and immune elicitation potential of the developed LacVax DNA-I. As compared with intramuscular injection, oral delivery of PPERDBY via L. lactis resulted in a significantly rapid increase in $\mathrm{IgG}$ and higher sIgA titers, indicating the immunogenic and immunostimulatory properties of the LacVax DNA-I. The needle-free immunization with LacVax DNA-I led to increased production of IL-4, an indicator of Th2 screwed response. To the best of our knowledge, this report for the first time outlines comparison of orally administered LacVax ${ }^{\circ}$ DNA-I with other conventional vaccination approaches.
\end{abstract}

\section{Introduction}

Vaccination is one of the most effective ways to prevent infection and disease establishment. Different strategies for vaccine development have been deployed against a wide range of pathogens [1]. Mucosal immunization with plasmid DNA has been studied with great interest in generating antigen-specific systemic as well as mucosal immunity [2].

Priti Desai

preetindesai79@gmail.com

preetindesai@yahoo.co.in

1 Department of Cell and Molecular Biology, B. V. Patel Pharmaceutical Education and Research Development (PERD) Centre, Ahmedabad, Gujarat, India

2 B. R. D. School of Biosciences, Sardar Patel University, Vallabh Vidhyanagar, Gujarat, India

3 Sardar Patel University, Vallabh Vidhyanagar, Gujarat, India

4 School of Biological Sciences \& Biotechnology, Institute of Advanced Research, Koba, Gandhinagar, Gujarat, India
Different bacterial carriers have been used for the delivery of DNA vaccines to mucosal sites. In the earlier attempts, attenuated invasive pathogens such as Salmonella, Shigella, Yersinia, and Listeria were used as a vaccine carrier [3]. The adhesive and invasive properties of these bacteria allow efficient DNA delivery to professional and non-professional phagocytes, leading to enhanced expression and presentation of antigen [4]. However, the major risk of reversion to virulent phenotype and associated safety issues discourage the use of attenuated invasive pathogens [3].

The use of food grade Lactococcus lactis (L. lactis) as a DNA delivery vehicle represents an attractive alternative to attenuated pathogens [3]. The GRAS (generally regarded as safe) status of L. lactis has paved the way for its application in oral delivery of antigens and numerous therapeutic molecules [5]. With this background, our group has explored L. lactis for the development of a mucosal vaccine against Shigella. We have reported efficient expression and delivery of outer membrane protein A (OmpA) of Shigella dysenteriae type-1 (SD-1) in $L$. lactis and evaluated its immunogenic potential in BALB/c mice $[5,6]$. 
In addition, we have also explored the potential use of non-invasive L. lactis and invasive L. lactis [7] for the delivery of the newly constructed DNA vaccine reporter plasmid; pPERDBY to Caco-2 cells [3]. The Escherichia coli $($ E. coli)-L. lactis shuttle vector; pPERDBY consists of eukaryotic expression cassette composed of the cytomegalovirus promoter (pCMV), a multiple cloning site fused with enhanced green fluorescent protein gene (MCSEGFP), and SV40 early mRNA polyadenylation signal, essential for gene expression by eukaryotic host cells. Moreover, the presence of two immunostimulatory $\mathrm{CpG}$ motifs strengthens the potential of pPERDBY as a prospective DNA vaccine plasmid. We demonstrated that the non-invasive recombinant $L$. lactis harboring $\mathrm{pPERDBY}$ (LacVax ${ }^{\oplus}$ DNA-I) successfully delivered pPERDBY to Caco-2 as determined by EGFP expression in co-cultured Caco-2 cells [3]. These results indicate the potential of noninvasive $L$. lactis to deliver DNA vaccine plasmid in vivo efficiently.

In the present study, LacVax DNA-I was administered orally to BALB/c mice to evaluate its in vivo DNA delivery potential. Moreover, the present study also characterized and compared the immune response elicited by LacVax ${ }^{\oplus}$ $D N A-I$ with other immunization approaches using EGFP as a model antigen. The systemic and mucosal immune response elicited against EGFP, following LacVax DNA-I immunization were compared with purified EGFP-OmpH protein and endotoxin-free plasmid pPERDBY, given intramuscularly to BALB/c mice.

The present article demonstrates the in vivo DNA delivery potential of LacVax DNA-I and evaluates its immunogenic response. To the best of our knowledge, this is the first report describing the comparison of immune response elicited by selected antigen when administered via different immunization strategies, i.e. naked DNA vs. purified protein vs. $\mathrm{r}-L$. lactis delivering the plasmid DNA in $\mathrm{BALB} / \mathrm{c}$ mice.

\section{Results}

\section{Confirmation of r-E. coli BL21 (DE3)::pCOLDII-EGFP- OmpH}

The vector maps of pCOLDII-EGFP-OmpH and pPERDBY are shown in Fig. 1a, b respectively. In order to attain high expression and yield of EGFP-OmpH, pCOLDII expression system was used in the present study. Colony PCR of transformants using egfp-specific primers resulted in the amplicon of $\sim 750 \mathrm{bp}$, which indicated the presence of pCOLDII-EGFP-OmpH in transformed $\mathrm{r}-E$. coli BL21 (DE3)::pCOLDII-EGFP-OmpH cells. Purified plasmid; pCOLDII-EGFP-OmpH and wild- type $E$. coli BL21 (DE3) served as a positive and negative control, respectively (Fig. 1c). The presence $\sim 5177 \mathrm{bp}$ band after digestion with EcoRV or HindIII indicated linearized pCOLDII-EGFP-OmpH (Lanes 2 and 3, Fig. 1d). The pCOLDII-EGFP-OmpH when double digested with EcoRV and HindIII resulted in two DNA fragments of 3106 and $2071 \mathrm{bp}$, confirming the successful construction of r-E. coli BL21 (DE3)::pCOLDII-EGFPOmpH (Fig. 1e).

\section{EGFP-OmpH expression and purification}

The expression of EGFP-OmpH was evaluated in uninduced and induced cell fractions of $\mathrm{r}-E$. coli BL21 (DE3):: pCOLDII-EGFP-OmpH by sodium dodecyl sulfatepolyacrylamide gel electrophoresis (SDS-PAGE) analysis (Fig. 2a, b). The presence of a $\sim 34.8 \mathrm{kDa}$ band in the induced cells and not in uninduced cells confirmed inducible expression of EGFP-OmpH (Fig. 2c).

After IPTG induction and incubation at low temperature, r-E. coli BL21 (DE3) harboring pCOLDII-EGFP-OmpH expressed EGFP-OmpH protein in an insoluble fraction which was then solubilized and subjected to Ni-NTA affinity purification. The presence of a $\sim 34.8 \mathrm{kDa}$ band in lane 5, 6, and 7 (Fig. 2c) confirms EGFP-OmpH expression and purification. The purified protein was then quantified by Bradford assay [8] (data not shown).

\section{Stability of DNA vaccine plasmid in LacVax DNA-I}

The stability of pPERDBY in our previously constructed DNA vaccine candidate LacVax DNA-I [3] was evaluated after repeated sub-culturing. It was found that around $91 \%$ and $94 \%$ of cells revived and formed colonies on GM17 agar in the absence and presence of chloramphenicol, respectively, suggesting stability of pPERDBY in developed DNA vaccine candidate.

\section{Humoral response after immunization with LacVax DNA-I and its comparison with conventional immunization methods}

We had previously shown the in vitro delivery of pPERDBY using non-invasive L. lactis [3]. To evaluate the in vivo DNA delivery potential of LacVax DNA-I and immune response elicitation post its immunization, serum IgG and fecal sIgA levels were analyzed. Moreover, the immune response elicited after LacVax DNA-I was compared with conventional methods of immunization, i.e. intramuscular (i.m.) injection of naked DNA and purified protein. Control groups were either immunized with saline (DS) or wild-type L. lactis (DW). The serum IgG of all the immunized mice was analyzed on day 0th, 20th, 43rd, and 

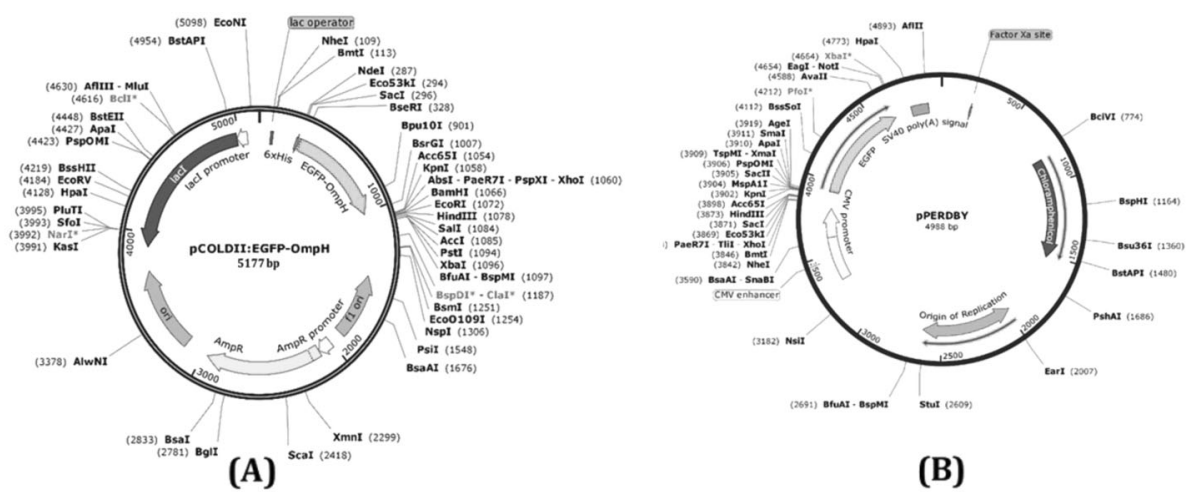

(B)

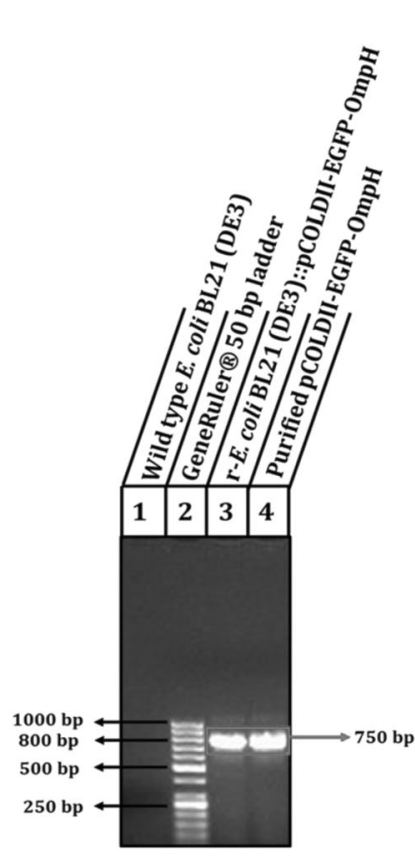

(C)

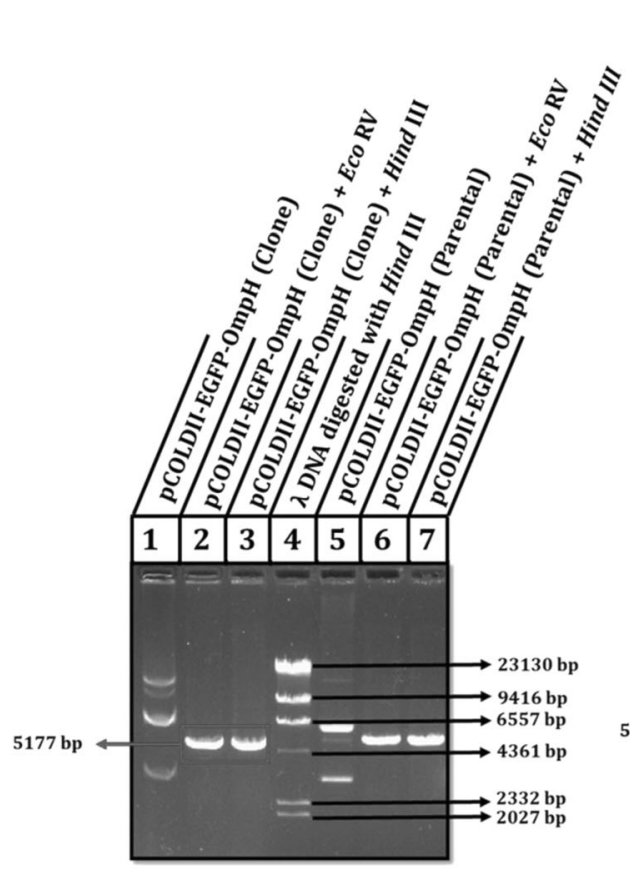

(D)

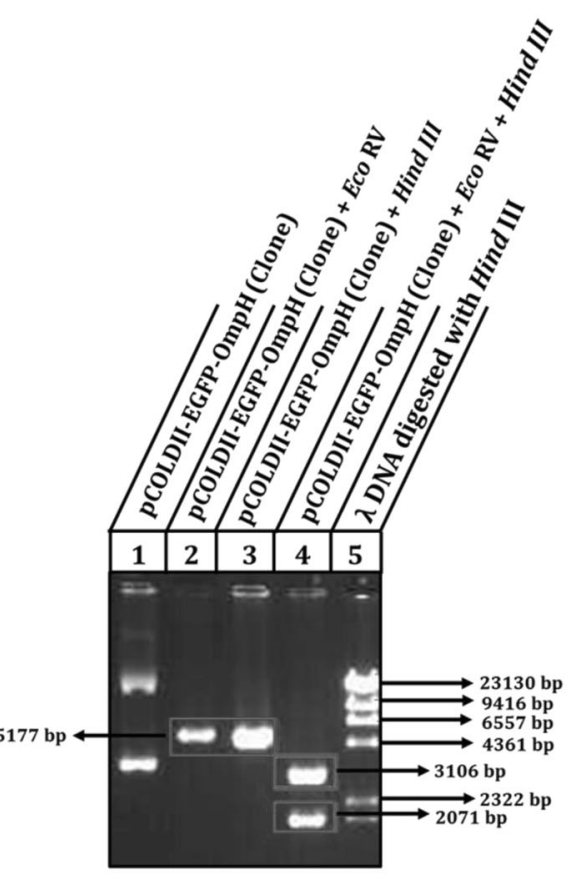

(E)

Fig. 1 Confirmation of pCOLDII-EGFP-OmpH. a Schematic representation of pCOLDII-EGFP-OmpH vector. b Schematic representation of pPERDBY vector. c A $1 \%$ agarose gel electrophoresis of $e g f p$-specific PCR amplicons; Lane-1: no band observed when PCR was performed using plasmid DNA isolated from wild-type E. coli BL21 (DE3); Lane 2: GeneRuler ${ }^{\circledR} 50$ bp ladder from Thermo Fisher Scientific, USA; Lane 3: a 750 bp PCR amplicon obtained using a plasmid template isolated from r-E. coli BL21 (DE3)::pCOLDII-EGFP-OmpH; Lane-4: a 750 bp PCR amplicon obtained using purified pCOLDII-EGFP-OmpH (positive control). d A $0.8 \%$ agarose gel electrophoresis of RE-digested plasmid samples isolated from r-E. coli BL21::pCOLDII-EGFP-OmpH; Lane-1: undigested plasmid sample isolated from r-E. coli BL21::pCOLDII-EGFP-OmpH; Lane 2: a 5177 bp linearized DNA sample following RE digestion of plasmid sample isolated from r-E. coli BL21:pCOLDII-EGFP-OmpH with EcoRV; Lane 3: a 5177 bp linearized DNA sample following RE digestion of plasmid sample isolated from r-E. coli BL21:pCOLDII-EGFPOmpH with HindIII; Lane-4: $\lambda$ DNA digested with HindIII; Thermo Fisher Scientific, USA; Lane 5: undigested plasmid pCOLDII-EGFP-OmpH sample received from Dr. Yong-Suk Jang; Lane-6: a 5177 bp linearized DNA sample following RE digestion of received pCOLDII-EGFP-OmpH with EcoRV; Lane-7: A 5177 bp linearized DNA sample following RE digestion of received pCOLDII-EGFP-OmpH with HindIII. e A $1 \%$ agarose gel electrophoresis of double digested plasmid samples isolated from r-E. coli BL21::pCOLDII-EGFP-OmpH; Lane-1: undigested pCOLDII-EGFP-OmpH; Lane 2: a 5177 bp linearized DNA sample following RE digestion of plasmid sample isolated from r-E. coli BL21:: pCOLDII-EGFP-OmpH with EcoRV; Lane 3: a 5177 bp linearized DNA sample following RE digestion of plasmid sample isolated from r-E. coli BL21:pCOLDII-EGFP-OmpH with HindIII; Lane-4: pCOLDII-EGFP-OmpH when digested with EcoRV and HindIII, it results in the generation of two DNA fragments of 3106 and $2071 \mathrm{bp}$, confirming the integrity of pCOLDII-EGFP-OmpH in r-E. coli BL21 (DE3) cells; Lane 5: $\lambda$ DNA digested with HindIII; Thermo Fisher Scientific, USA

49th, whereas fecal $\operatorname{sig}$ A was analyzed after the 7th day of the last immunization (day 49th).

As shown in Fig. 3a, b, on day 49, IgG titers of LacVax DNA-I-immunized BALB/c mice (Group DR) were higher than that of the DIM group which was immunized intramuscularly with endotoxin-free pPERDBY. However, immunization with purified EGFP-OmpH (Group P) resulted in the highest IgG titers (Fig. 3a). On the other hand, mice immunized with phosphate-buffered saline (PBS) (Group DS) or wild-type L. lactis (DW) did not exhibit 


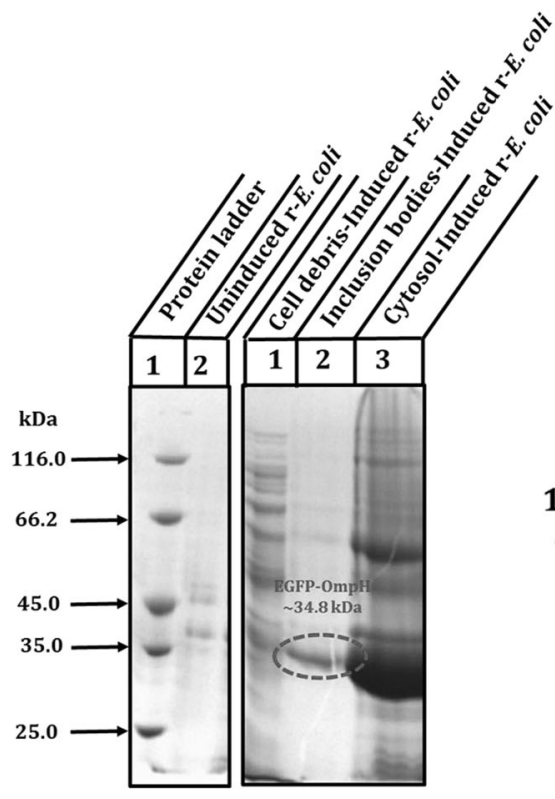

(A)

(B)

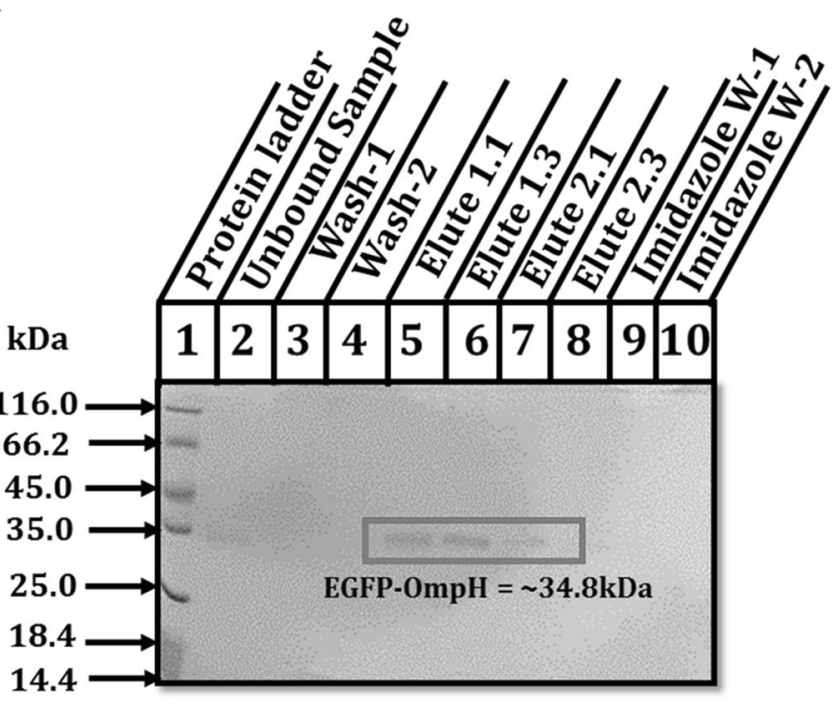

(C)

Fig. 2 EGFP-OmpH expression and purification from r-E. coli BL21::pCOLDII-EGFP-OmpH. a A 10\% SDS-PAGE of uninduced r-E. coli BL21::pCOLDII-EGFP-OmpH cells: Lane-1: Pierce ${ }^{\mathrm{TM}}$ Unstained Protein MW Marker; Thermo Fisher Scientific, USA; Lane 2: uninduced r-E. coli BL21::pCOLDII-EGFP-OmpH cells mixed with the SDS-PAGE loading dye (reducing). b A 10\% SDS-PAGE of different cellular fractions of induced r-E. coli BL21:pCOLDII-EGFP-OmpH: Lane-1: bacterial cell debris; Lane 2: solubilized inclusion bodies; Lane 3: cytosolic matter. c A 12\% SDS-PAGE of purification samples of induced r-E. coli BL21:pCOLDII-EGFP-OmpH: Lane-1: Pierce ${ }^{\mathrm{TM}}$ Unstained Protein MW Marker; Thermo Fisher Scientific, USA; Lane 2: Unbound protein sample collected after the loading of protein fraction; Lanes 3 and 4: Protein sample fractions collected as a part of column washing steps; Lanes 5-8: Protein sample fractions collected as a part of elution step; Lanes 9 and 10: Samples obtained as a part of final wash step

EGFP-specific antibodies (Fig. 3a). The EGFP-specific serum IgG antibodies increased in Group DR and DIM with each round of immunization (Fig. 3c). Interestingly, the EGFP-specific serum antibodies increased significantly immediately after the third dose of LacVax ${ }^{\oplus}$ DNA-I $\left(20^{\text {th }}\right.$ day), which was not in the case of naked DNA immunization (DIM group). Also, the production of antigenspecific IgG was rapid and titers were high in LacVax DNA-I immunized mice as compared to the DIM group. On the 49th day, i.e., 7 days after the last booster, there were significantly higher EGFP-specific serum IgG antibodies in DR $(P=0.039)$ and DIM $(P=0.0023)$ groups of mice. IgG levels remained constant in control groups DS and DW over the entire dosage regimen (Fig. 3c).

The production of $\operatorname{sIg} \mathrm{A}$, a hallmark of mucosal priming, was evident in mice immunized with LacVax DNA$I$, naked pPERDBY, and purified EGFP-OmpH. Interestingly, antigen-specific fecal sIgA levels of LacVax $D N A-I$ immunized animals were similar to that of mice immunized with purified EGFP-OmpH $(P<0.0001)$ and higher than the DIM group of mice which were immunized with naked pPERDBY. As anticipated, control groups: DS and DW, showed an insignificant rise in fecal IgA (Fig. 3d).

\section{Cell mediated immune activation}

In an attempt to evaluate and compare the activation of cellular immunity, by different modes of immunization, we have estimated IFN- $\gamma$ (a representative Th1 cytokine) and IL-4 (a representative Th2 cytokine) production in immunized mice. As evident from Fig. 4a, the IL-4 levels are significantly elevated in the groups P, DR, and DIM as compared to the control groups DS and DW. As shown in Fig. 4b, i.m. injection of pPERDBY resulted in an indicative Th1 cellular response, whereas delivery of the same plasmid by oral route via $r-L$. lactis resulted in an indicative Th2 response. Immunization with purified EGFP-OmpH revealed an indicative Th2 response (Fig. $4 \mathrm{~b}$ ), which can be correlated with significantly higher IgG titers (Fig. 3a) in Group P. The indicative Th2 response in the DR group compared to DIM supports the early rise in IgG levels in the DR group on the 20th day (Fig. 3c).

\section{Integrity of intestinal tissues}

To investigate the tissue integrity of orally LacVax ${ }^{\oplus}$ DNA-I immunized $\mathrm{BALB} / \mathrm{c}$ mice, we performed $\mathrm{H} \& \mathrm{E}$ staining of the small and large intestine of DR, DW, and DS groups. Of 
(A)

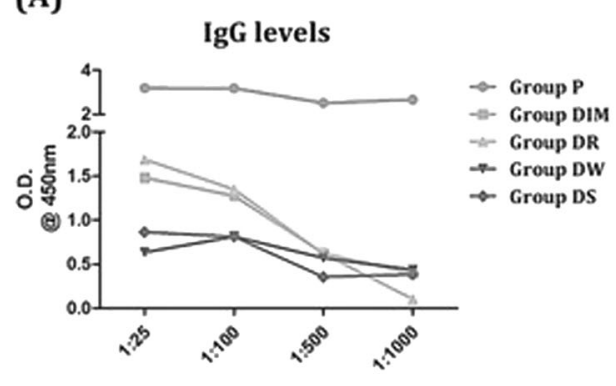

(C)

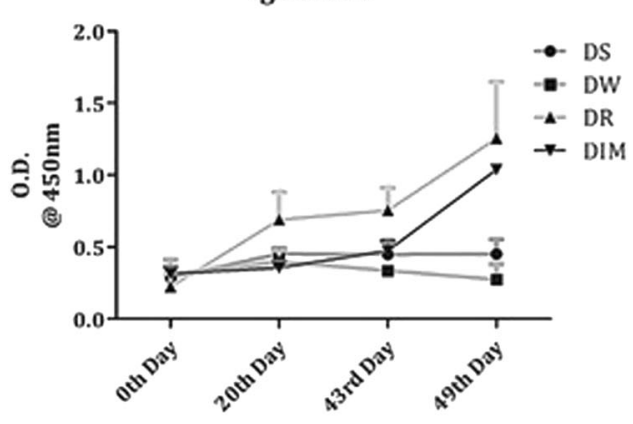

(B)

\section{IgG levels on Day 49}

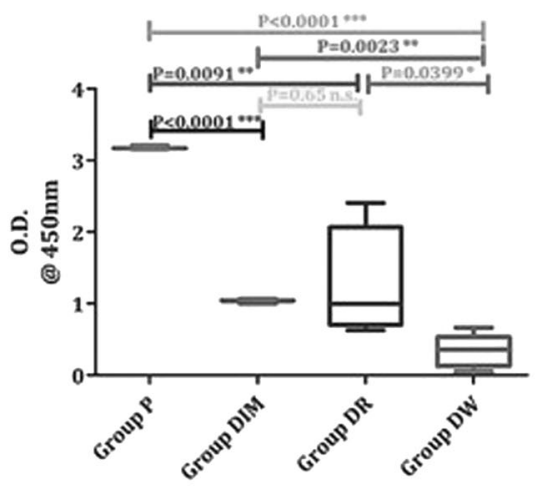

(D)

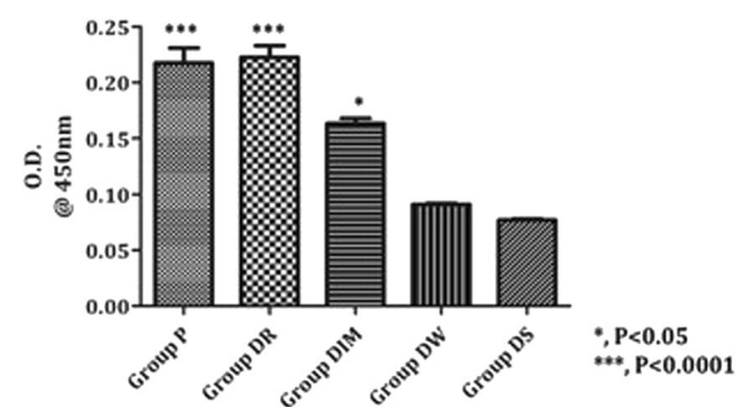

Fig. 3 Humoral responses of immunized animals. a Serum IgG levels of all immunized animals on 49th day. b Serum IgG levels of LacVax immunized mice (Group DR), pPERDBY injected BALB/c mice (Group DIM), Purified EGFP-OmpH immunized mice (Group P), and wild-type L. lactis NZ9000 (Group DW) on day 49th. c IgG levels of group DR, DIM, DW, and DS mice at different time intervals. d Fecal sIgA levels of all immunized groups on day 49th

note, oral inoculation of LacVax DNA-I did not induce inflammatory or structural changes. The physiological characteristics of the DR group were similar to that of control groups: DS and DW (Fig. 4b), indicating the safe profile of LacVax DNA-I.

\section{Discussion}

A number of enteric pathogens breach host mucosal epithelial barrier and establish infections [9]. To combat against these infectious agents, induction of mucosal immunity in addition to systemic immunity is essential and can be achieved by efficient delivery of antigens or vaccine candidates at the site of infection [1]. Different vaccination approaches such as immunization with naked plasmid DNA and subunit vaccines are in practice. However, these nonliving vaccines require larger dose and fail to induce cellular immunity with long lasting humoral immunity that is essential to provide protection against pathogens [10]. Moreover, these immunization procedures are cumbersome and use syringes and needles for vaccine administration [10]. Considering the patient compliance, unsafe usage, cost, and rapid increase in the incidents of cross- contamination, World Health Organization has accelerated the search for safer and needle-free strategies of immunization [11-13].

In the search for needle-free mucosal vaccination, live bacterial carriers such as attenuated pathogens were exploited for DNA as well as antigen delivery. Such vaccine carriers have minimal virulence but offer high immunogenicity and hence their use was promising in earlier attempts for, e.g., Salmonella enterica, Shigella flexneri, Listeria monocytogenes, and Yersinia enterocolitica. However, the unmitigated risk of reversion has triggered the hunt for safer yet live vaccine carriers [14]. Food grade bacteria such as L. lactis when used as an antigen delivery vehicle provides advantages similar to that of attenuated pathogens and is safe even for immunocompromised individuals and children [15]. Apart from antigen delivery vehicle, L. lactis has recently been exploited as a DNA delivery vehicle $[3,4$, 16-19].

We had previously shown successful delivery of DNA vaccine reporter plasmid; pPERDBY to Caco-2 cells by non-invasive $\mathrm{r}-L$. lactis::pPERDBY and demonstrated EGFP expression in vitro [3]. In the present study, we investigated in vivo DNA delivery potential of the developed non-invasive $\mathrm{r}-L$. lactis harboring pPERDBY 
(A)

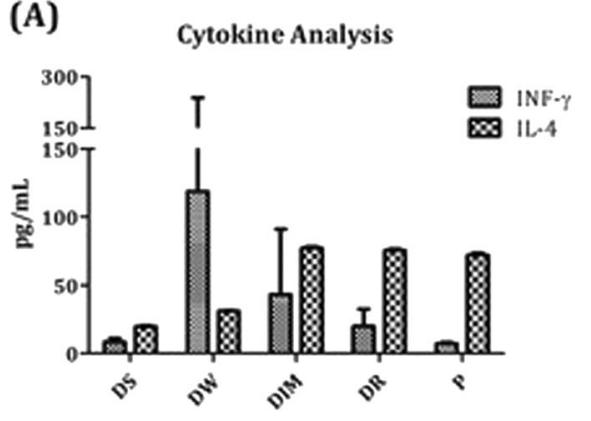

(B)

Ratio (Th1/Th2)

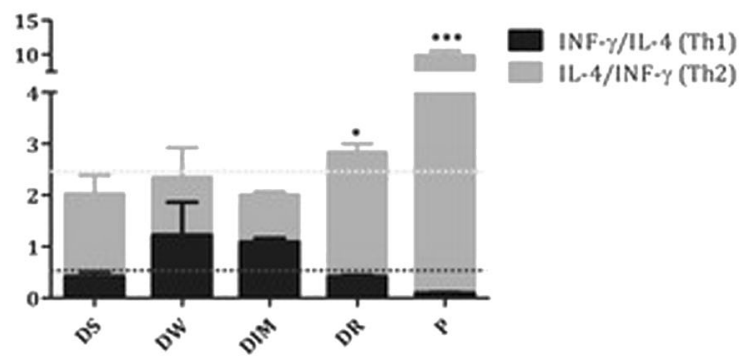

(C)
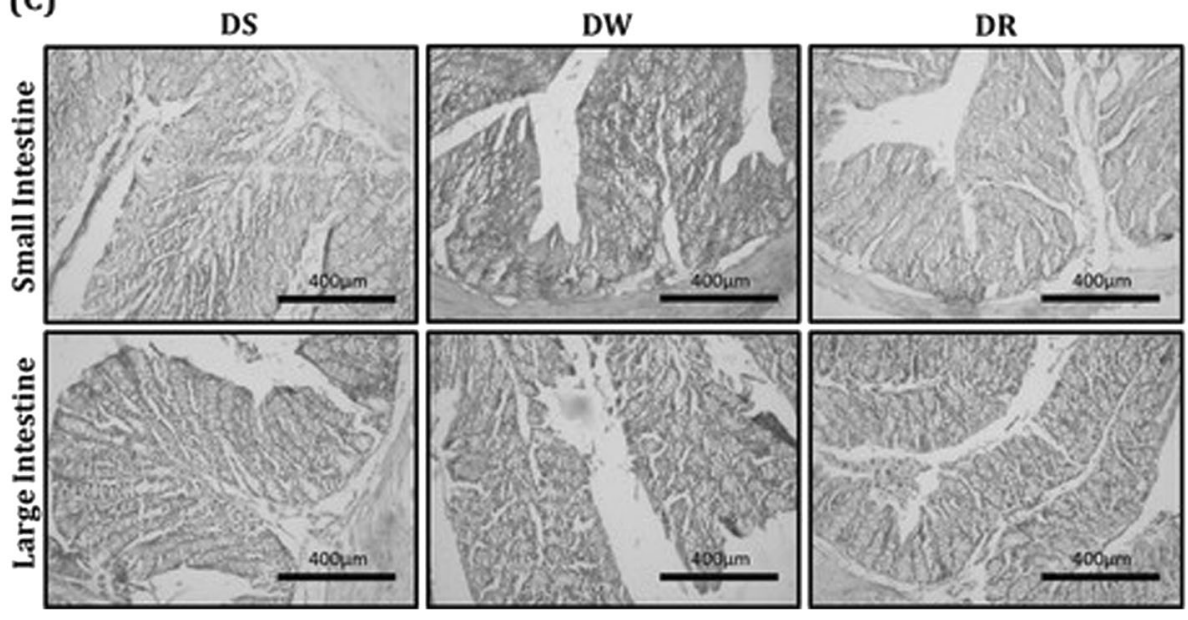

Fig. 4 Cellular immune response of immunized animals and safety profile of LacVax ${ }^{\bullet}$ a INF- $\gamma$ and IL-4 levels in all the immunized animals. b INF- $\gamma /$ IL-4 cytokines ratio (an indicative Th1/Th2 ratio) of all immunized groups. c H\&E staining of the small intestine and large intestine samples of DS, DW, and DR group

(LacVax DNA-I) and evaluated the immunogenic potential of LacVax DNA-I, using EGFP as a model antigen. Moreover, the cellular and humoral response elicited following LacVax DNA-I immunization were compared with the conventional vaccination approaches.

EGFP has been widely used as an intracellular reporter molecule to assess the gene transfer [20]. Mancha-Agresti et al. [21] in 2016 have shown the expression of EGFP in enterocytes of BALB/c mice following the delivery of pExu:egfp by L. lactis MG1363 [21]. Moreover, Stripecke et al. in 1999 have reported immunogenic potential of EGFP to induce cellular and humoral immunity in BALB/c mice [22, 23] and rhesus macaque monkey [24]. Hence, in the present study, EGFP was employed to assess gene delivery and to compare and characterize immune response following alternate vaccination strategies.

Oral administration of purified naked plasmid DNA harboring GFP or GFP variants result in no $g f p$ expression at mRNA and protein levels [25-27], indicating complete degradation of plasmid administered via oral route. In contrast, serum IgG, fecal $\operatorname{sIgA}$, and cellular responses achieved with oral administration of our LacVax DNA-I suggest not only protection of the plasmid; pPERDBY from degrading enzymes but also indicate efficient delivery of the plasmid DNA to epithelial cells and antigen-presenting cells (APCs). These findings reinforce the potential of LacVax $D N A-I$ in surviving the enzymatic environment and low $\mathrm{pH}$ of the stomach.

Moreover, oral inoculation of LacVax DNA-I resulted in an increase in EGFP-specific IgG and sIgA. The restimulation of splenocytes of LacVax DNA-I immunized animals with EGFP-OmpH resulted in an indicative Th2 cytokine response. Previous studies by J-M Chatel et al. demonstrated the delivery of BLG cDNA using noninvasive L. lactis to $\mathrm{BALB} / \mathrm{c}$ mice. However, they failed to detect fecal $\operatorname{sIg} \mathrm{A}, \operatorname{IgG}$, and cytokine secretion after re-stimulation with purified BLG in vitro [28]. The probable reasons for the observed differences could be: (a) the differences in the backbone of the plasmids used in both the studies, (b) the large size of the plasmid used; pLIG-BLG1 $(10.9 \mathrm{~kb})[17,28]$, whereas our constructed PPERDBY is one of smallest DNA vaccine reporter plasmid $(\sim 4.9 \mathrm{~kb})[3]$. The small plasmid size facilitates better transformation efficiency [29], which induces a strong immune response, (c) The antigen in both the studies was different, attributing towards the observed immune differences.

Our hypothesis of immune elicitation following the in vivo delivery of pPERDBY by food grade lactic acid bacteria 


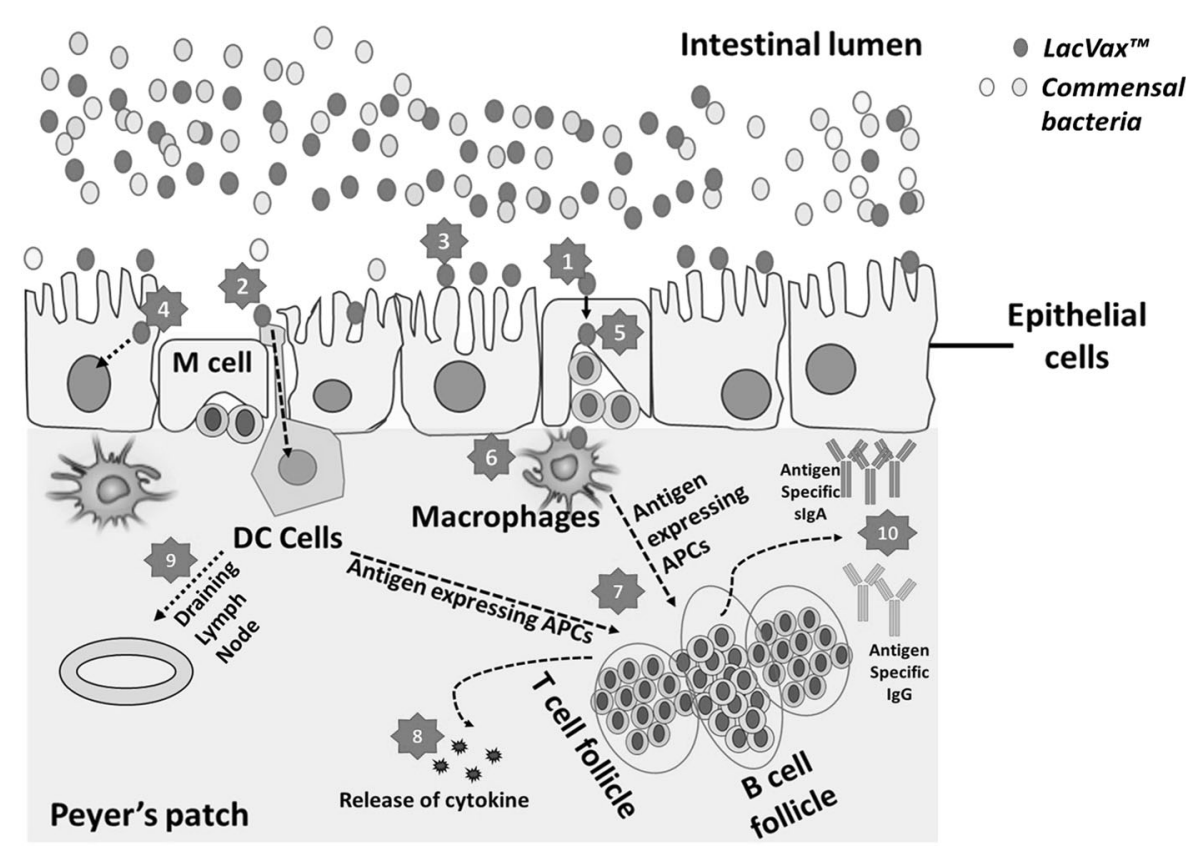

Fig. 5 Hypothesis of in vivo DNA delivery and immune stimulation by LacVax . (1) Entry of LacVax inside M cells; (2) sampling of antigen (LacVax ${ }^{\circ}$ ) by DC cells; (3) adhesion of LacVax to epithelial cells; (4) endocytosis of LacVax inside epithelial cells and DNA delivery to nucleus; (5) transfer of LacVax to B cells and/or T cells via M cell pocket; (6) antigen uptake (LacVax ) by macrophages; (7) antigen presentation to T cells and B cell follicles by antigen loaded APCs; (8) release of cytokines by antigen stimulated T cells; (9) movement of antigen captured DC cells towards draining lymph nodes; (10) production of IgG and sIgA by stimulated B cells

(LAB) is adhesion of $L$. lactis to epithelial cells or M cells [30], resulting in the entry of $L$. lactis inside epithelial cells or $\mathrm{M}$ cells $[3,27,31]$. The internalized bacteria is being lysed inside epithelial cells or gets translocated via $\mathrm{M}$ cells. The $\mathrm{M}$ cell translocated bacteria may get engulfed and lysed by antigen-presenting cells (APCs) [32]. The plasmids released from the lysed bacteria enter into the nucleus of epithelial cells or APCs, resulting in gene expression and antigen presentation (Fig. 5) [2]. The proposed hypothesis is strengthened by other researchers and astonishing observation that certain LAB strains and commensal bacteria such as Enterobacter cloacea are known to penetrate dendritic cells and able to reside within the cells for several days [3, 28, 33-35]. The outcomes and the hypothesis of the present study are in line with the recent findings of Mancha-Agresti et al., 2016, who could successfully show EGFP expression in the enterocytes of BALB/c mice following the delivery of pExu:egfp using non-invasive L. lactis. However, they have not evaluated the immunogenic response elicited against the model antigen EGFP [21].

Although, the i.m. injection of plasmid pPERDBY resulted in gradual increase in EGFP-specific IgG, the significant increase in IgG levels was evident only on the last booster dose (day 49th). In contrast, oral immunization with LacVax ${ }^{\oplus}$ DNA-I resulted in significant rise in IgG antibodies immediately after the third dose (20th day). The observed differences in the immune response between the two groups could be due to the differences in the route of immunization and the effective antigen concentration, presented to the immune system. Moreover, i.m. injection of naked DNA failed to produce significant $\operatorname{sIg} \mathrm{A}$, indicating the shortcoming of intramuscularly injected DNA vaccines. These findings are in accordance with the previous studies which demonstrated the weak potential of intramuscularly injected plasmid DNA in evoking mucosal immunity [2, 36, 37]. Interestingly, i.m. injection of pPERDBY resulted in an indicative Th1 response, whereas delivery of the same plasmid via $L$. lactis resulted in an indicative Th2 response, attributing immunomodulatory adjuvant properties of $L$. lactis [38, 39]. Moreover, the observed differences in cytokine profile of DS and DW groups also support the immunostimulatory properties exerted by wild-type $L$. lactis upon repeated administration to BALB/c mice. The high ratio of Th2/Th1 response in DR mice can be correlated with a high and early rise in $\mathrm{IgG}$ of the DR group.

Though protein immunization resulted in highest $\operatorname{IgG}, \operatorname{IgA}$ titers and an indicative Th2 cellular response, poor stability of protein vaccine candidate, batch to batch variability and inability to induce an indicative Th1 immune response, discourage its application as a subunit vaccine for enteric pathogens [10]. Moreover, protein immunization via the oral route results in antigen degradation and weak immune stimulation [40]. Remarkably, the LacVax DNA-I immunization could achieve similar sIgA response and better Th1 response as compared to protein immunization, reinforcing the potential of LacVax DNA-I as an oral mucosal vaccine carrier. 
Table 1 Bacterial strains and plasmids used in the study

\begin{tabular}{|c|c|c|}
\hline Strains or plasmids & Characteristics & Reference \\
\hline \multicolumn{3}{|l|}{ Strains } \\
\hline E. coli $\mathrm{BL} 21$ (DE3) & $\mathrm{F}^{-}$omp $\mathrm{T} h s d S\left(\mathrm{rb}^{-} \mathrm{mb}^{-}\right)$gal dcm $\lambda(\mathrm{DE} 3)$ nin5 lac $\mathrm{UV}-\mathrm{T} 7$ & Lab Source \\
\hline $\begin{array}{l}\text { r- E. coli BL21 (DE3):: } \\
\text { pCOLDII:EGFP-OmpH }\end{array}$ & $\begin{array}{l}\mathrm{Amp}^{\mathrm{r}} \text {, E. coli BL21(DE3) harboring pCOLDII:EGFP-OmpH plasmid, lac } \\
\text { operon }\end{array}$ & This work \\
\hline L. lactis NZ9000 & $\begin{array}{l}\text { L. lactis subsp. cremoris (derivative strain of MG1363, carrying nisRK } \\
\text { genes on the chromosome) }\end{array}$ & $\begin{array}{l}\text { Gift from Dr. Luis Bermudez- } \\
\text { Humaran, INRA, France }\end{array}$ \\
\hline $\begin{array}{l}\text { LacVax DNA-I (r-L. lactis:: } \\
\text { pPERDBY) }\end{array}$ & $\mathrm{Cm}^{\mathrm{r}}, \mathrm{NZ9000}$ harboring pPERDBY & [3] \\
\hline \multicolumn{3}{|l|}{ Plasmids } \\
\hline pCOLDII-EGFP-OmpH & $\begin{array}{l}\text { Amp }{ }^{\mathrm{r}} \text {, His-tagged } e g f p \text {, lac operon, EGFP is fused with a small peptide, } \\
\text { outer membrane protein } \mathrm{H}(\mathrm{OmpH}) \text { of } \sim 2.1 \mathrm{kDa} \text {. OmpH is M cell ligand, } \\
\text { used for targeted mucosal delivery }\end{array}$ & Gift from Dr. Yong-Suk Jang \\
\hline pPERDBY & $\begin{array}{l}\mathrm{Cm}^{\mathrm{r}}, \mathrm{P}_{\mathrm{CMV}} \text { fused to } e g f p \text { gene, E. coli-LAB shuttle vector. GenBank } \\
\text { Accession No.: KR072508.1 }\end{array}$ & {$[3]$} \\
\hline
\end{tabular}

Chloramphenicol (Cm) was used at $10 \mu \mathrm{g} / \mathrm{ml}$ for E. coli and L. lactis. Ampicillin (Amp) at $100 \mu \mathrm{g} / \mathrm{ml}$ was used for E. coli

In conclusion, the developed non-invasive LacVax $D N A-I$ delivery platform is not only capable of delivering pPERDBY but could also elicit systemic and mucosal immune response. The LacVax DNA-I, as a vaccine delivery platform, offers several benefits such as low production cost, safe profile, and needle-free administration which is convenient for mass immunization [41]. Furthermore, the immunostimulatory adjuvant properties of $L$. lactis help to counteract vaccine loss and make up for the lower immunogenicity of non-living DNA vaccines $[2,10$, 42]. Moreover, the present work for the first time outlines the immune comparison of orally administered LacVax $D N A-I$ with conventional vaccination approaches. Efficient antigen delivery at the intestinal tissue is one of the major hurdles in the mucosal vaccine development.

The promising findings of the present work demonstrate the potential of LacVax DNA-I-based platform in targeting antigens of enteric pathogens at various mucosal sites. However, further studies involving detailed characterization of Th1 and Th2 cytokines and in vivo challenge are warranted to establish the effectiveness of LacVax DNA-I as a vaccine delivery platform. Currently, we are evaluating the immunogenic potential of LacVax OmpA-I, harboring ompA gene of SD-1 in BALB/c mice in line to provide candidate Shigella vaccine.

\section{Materials and methods}

\section{Bacterial strains and plasmids}

Bacterial strains and plasmids used in the study are listed in Table 1. E. coli DH5 $\alpha$ and BL21 (DE3) strains were grown in Luria-Bertani (LB) medium at $37{ }^{\circ} \mathrm{C}$ with vigorous shaking. L. lactis NZ9000 was grown statically at $30^{\circ} \mathrm{C}$ in
M17 medium (Difco Laboratories, USA) supplemented with $0.5 \%$ glucose (GM17). Antibiotics were added at the indicated concentration as necessary: Chloramphenicol $(\mathrm{Cm}), 10 \mu \mathrm{g} / \mathrm{ml}$ for E. coli and L. lactis and Ampicillin (Amp), $100 \mu \mathrm{g} / \mathrm{ml}$ for E. coli.

\section{Construction of recombinant E. coli BL21 (DE3):: pCOLDII-EGFP-OmpH strain}

Chemical $\left(\mathrm{CaCl}_{2}\right)$ competent cells of E. coli BL21 (DE3) were prepared and transformed with pCOLDII-EGFP$\mathrm{OmpH}$, received as a gift sample from Dr. Yong-Suk Jang [43], by heat-shock method as described by Sambrook and Russel [44]. Transformants were selected on Luria Agar (LA) plates containing $100 \mu \mathrm{g} / \mathrm{ml}$ of Ampicillin. The plasmid was purified from $\mathrm{r}-E$. coli culture using GeneJet Plasmid Miniprep Kit (Thermo Fischer Scientific) according to the manufacturer's protocol. The presence of $e g f p$ was detected using the following oligonucleotides: EGFPForward: 5'-AGCGTCGACATGGTGAGCAAGGGCG-3' and EGFP-Reverse: 5'-ACGGATATCGGTTTCACGCGC AGGTA-3'. Restriction enzymes (REs), i.e., EcoRV and HindIII and polymerase chain reaction (PCR) components (Taq polymerase, dNTPs, $\mathrm{MgCl}_{2}$, and Taq polymerase buffer) were used as recommended by the manufacturer (Thermo Scientific, USA).

\section{Protein expression and purification}

Recombinant $E$. coli BL21 (DE3) cells harboring pCOLDIIEGFP-OmpH were used to express EGFP-OmpH. Briefly, $\mathrm{r}-E$. coli BL21 (DE3) strain was grown at $37^{\circ} \mathrm{C}$ at 180 revolutions per minute (rpm) until an optical density of 600 $\mathrm{nm}\left(\mathrm{OD}_{600}\right)$ was reached to 0.4-0.6. This followed by refrigerating the culture at $15^{\circ} \mathrm{C}$ for $30 \mathrm{~min}$. The culture 
was then induced with $0.4 \mathrm{mM}$ isopropyl- $\beta$-D-1-thiogalactopyranoside (IPTG) and incubated at $15^{\circ} \mathrm{C}$ for $24 \mathrm{~h}$ with continuous shaking at $180 \mathrm{rpm}$. To ensure the induction of EGFP-OmpH expression, induced and uninduced cells were subjected to $12 \%$ SDS-PAGE.

Recombinant His-tagged EGFP-OmpH was purified by nickel affinity chromatography as described by Yagnik et al. [5]. Briefly, induced recombinant cells were sonicated in lysis buffer (8 M Urea; $0.1 \mathrm{M} \mathrm{NaH}_{2} \mathrm{PO}_{4} ; 0.01 \mathrm{M}$ Tris-Cl; $\mathrm{pH}$ 8.0) and centrifuged at $10,000 \mathrm{~g}$ for $30 \mathrm{~min}$. The lysate was then mixed with 50\% Ni-NTA slurry $(4: 1)$ and kept at $4{ }^{\circ} \mathrm{C}$ for $16 \mathrm{~h}$. Ni-NTA slurry was loaded on the column and the EGFP-OmpH protein was eluted using acidic elution buffer (8 M Urea; $0.1 \mathrm{M} \mathrm{NaH}_{2} \mathrm{PO}_{4} ; 0.01 \mathrm{M}$ Tris-Cl; $\mathrm{pH} 4.5$ ) after washing with wash buffer ( $8 \mathrm{M}$ Urea; $0.1 \mathrm{M} \mathrm{NaH}_{2} \mathrm{PO}_{4}$; $0.01 \mathrm{M}$ Tris-Cl; $\mathrm{pH} 6.3$ and 5.9). Affinity purified fraction was dialyzed in the phosphate-buffered saline (PBS; $10 \mathrm{M}$ $\mathrm{Na}_{2} \mathrm{HPO}_{4} ; 137 \mathrm{M} \mathrm{NaCl} ; 2.7 \mathrm{M} \mathrm{KCl}$ and $1.8 \mathrm{M} \mathrm{K}_{2} \mathrm{HPO}_{4}$ ) and quantified by Bradford assay [8]. Different fractions of purified protein were then subjected to $12 \%$ SDS-PAGE.

\section{Stability of DNA vaccine candidate}

Stability of pPERDBY in our previously constructed recombinant L. lactis NZ9000 (LacVax DNA-I) [3] was evaluated as described by Hongying et al. [45], with minor modifications. A frozen glycerol stock of $\mathrm{r}-L$. lactis NZ9000::pPERDBY was diluted (1:25) in GM17 broth and grown to an $\mathrm{OD}_{600}$ of 0.9 . The preliminary culture was further sub-cultured at least 25 times in GM17 broth and grown at $30^{\circ} \mathrm{C}$ statically. Both the cultures were plated on GM17 agar with or without chloramphenicol $(10 \mu \mathrm{g} / \mathrm{ml})$ and incubated at $30^{\circ} \mathrm{C}$ for $16 \mathrm{~h}$. The numbers of colony-forming units (CFU) recovered on GM17 agar plates with or without chloramphenicol were compared with the CFU count of LacVax ${ }^{\circ}$ DNA$I$ at the time of glycerol stock preparation in order to evaluate the stability of pPERDBY in $\mathrm{r}-L$. lactis NZ9000. The percentage stability was calculated using the following equation:

\section{Stability $(\%)$ \\ $=\frac{\mathrm{CFU} \text { count of } L a c V a x^{\oplus} D N A-I \text { at the time of revival }}{\mathrm{CFU} \text { count of } \operatorname{LacVax}{ }^{\oplus} D N A-I \text { at the time of glycerol stock preparation }} \times 100$}

\section{Animal immunization}

Six- to eight-week-old female BALB/c mice, weighing 25-30 g, were used in the study. Pathogen-free BALB/c mice were procured from Mahaveera Enterprises, Hyderabad, India and housed in B. V. Patel PERD Centre's animal house in accordance with Committee for the Purpose of Control and Supervision of Experiments on Animals (CPCSEA) guidelines. All animal experiments were done in accordance with the institutional animal ethics committee.
Animals were randomly divided into different groups by a technician who was blind to the study design. However, the investigators were not blinded to the group allocation or analysis. Groups of six mice were immunized as described in Table 2. For DNA immunization, $30 \mu \mathrm{L}$ of purified endotoxin-free plasmid pPERDBY $(0.83 \mu \mathrm{g} / \mu \mathrm{l})$ was administered intramuscularly. For protein immunization, purified EGFP-OmpH ( $3 \mu \mathrm{g} / 33 \mu \mathrm{l})$ was emulsified with two volumes of Freund's complete adjuvant and for subsequent immunizations with Freund's incomplete adjuvant and administered intramuscularly. Saline and wild-type $L$. lactis NZ9000 receiving groups were used as controls in the present study. The LacVax DNA-I and wild-type L. lactis NZ9000 cultures were grown as described in the Materials and methods section and resuspended to the $10^{8} \mathrm{CFU}$ per $100 \mu \mathrm{l}$ for oral immunization.

\section{Enzyme-linked immunosorbent assay (ELISA) for the detection of EGFP-specific antibodies}

Antigen-specific serum IgG and fecal secretory $\operatorname{Ig}$ A ( $\operatorname{Ig} \mathrm{A}$ ) antibodies were detected by ELISA as described by Yagnik et al. [5], with minor modifications. Briefly, test wells of 96well microtiter plates (Medisorp, Thermo Scientific Nunc) were coated with $300 \mathrm{ng}$ per well of purified EGFP-OmpH whereas $100 \mu \mathrm{l}$ of PBS was added to the blank wells. Plates were then incubated at $2-8{ }^{\circ} \mathrm{C}$ overnight followed by decanting the unbound antigen. Free sites were blocked for $3 \mathrm{~h}$ with $250 \mu \mathrm{l}$ of $2 \%$ bovine serum albumin in PBS at $37^{\circ}$ C. Serum sample (100 $\mu \mathrm{l} ; 1: 100$ dilution) or homogenized fecal sample (100 $\mu \mathrm{l} ; 1: 5$ dilution) was added and incubated for $2 \mathrm{~h}$ at $37^{\circ} \mathrm{C}$. After incubation, wells were washed thrice with $100 \mu$ of wash solution [PBS containing $0.02 \%$ (v/v) Tween 20]. For detection of bound antibodies, $100 \mu \mathrm{l}$ of HRP-conjugated goat anti-mouse antibodies were added at 1:1000 dilution and incubated for $2 \mathrm{~h}$ at $37^{\circ} \mathrm{C}$. After incubation, wells were washed thrice with $100 \mu$ l of wash solution. Bound antibodies were revealed with TMB $\left(3,3^{\prime}, 5,5^{\prime}\right.$-tetramethylbenzidine) substrate solution in sterile water and incubated in dark at $37^{\circ} \mathrm{C}$ for $15 \mathrm{~min}$. The reaction was stopped by the addition of $50 \mu \mathrm{l}$ of $2 \mathrm{M} \mathrm{H}_{2} \mathrm{SO}_{4}$. Absorbance at $450 \mathrm{~nm}$ was read with a Multiskan GO microplate spectrophotometer (Thermo Scientific, USA).

\section{Cytokine profiling}

All mice were sacrificed on the seventh day of the last booster dose and spleens were removed. Splenocytes were isolated as described previously by Pore et al. [46] and Ahmed et al. [40], with minor modifications. Briefly, the single cell suspension was prepared from isolated spleen in Hanks balanced salt solution medium using a $40 \mu \mathrm{m}$ nylon cell strainer. After erythrocytes lysis, cells were 
resuspended in RPMI 1640 medium at a concentration of $3 \times 10^{6} / 0.5 \mathrm{~mL}$ and cultured in a 24 -well plate. Cells were stimulated with $3 \mu \mathrm{g}$ EGFP-OmpH protein for $24 \mathrm{~h}$. Thereafter, supernatants were collected and analyzed for quantification of IL-4 and $\mathrm{INF}^{-} \gamma$ using mouse Th1/Th2 ELISA Ready-SET-Go kit (eBioscience), according to the manufacturer's instructions.

\section{Histopathological staining and examination}

In order to determine the safety profile of orally administered LacVax ${ }^{\oplus} D N A-I$, the intestinal tissues of LacVax DNA-I immunized mice were collected and compared with the intestinal tissues of saline and wild-type L. lactisimmunized animals. All the animals were immunized as described in Table 2. After the seventh day of the last booster dose, animals were euthanized and small and large intestine from the DS, DW, and DR group were excised. Tissues were subjected to hematoxylin and eosin (H\&E) staining. The stained tissue samples were examined under the light microscope (Olympus Model IX51).

\section{Statistical analysis}

Statistical analyses were performed using GraphPad Prism (trial version 5). One-way ANOVA with post hoc Bonferroni's multiple comparison test was used to determine the statistical significance of cytokine levels and $\operatorname{sIgA}$ among experimental groups at different time intervals. Two-way ANOVA with post hoc Bonferroni's multiple comparison test was used to determine the significant differences in IgG levels of different groups at different time intervals. Data are presented as the mean \pm standard error of mean (SEM). $P$-values of $<0.05$ were considered as significant.

Acknowledgements We gratefully acknowledge Dr. Luis BermudezHumaran, INRA, France for the gift of L. lactis NZ9000. We also extend our sincere thanks to Dr. Yong-Suk Jang, Jeonju, Korea for the gift of pCOLDII-EGFP-OmpH. Mr. Bhrugu Yagnik is a recipient of a Lady Tata Memorial Fellowship (JRS-2014 \& SRS-2016). We thank Mr. Saurabh Patel, NIPER, Ahmedabad for helping us with the construction of $\mathrm{r}-E$. coli BL21 (DE3)::pCOLDII-EGFP-OmpH. This research has been facilitated by the infrastructure and resources provided by B. V. Patel PERD Centre.

\section{Compliance with ethical standards}

Conflict of interest The authors declare that they have no conflict of interest.

\section{References}

1. Holmgren J, Svennerholm AM. Vaccines against mucosal infections. Curr Opin Immunol. 2012;24:343-53. 
2. Gurunathan S, Klinman DM, Seder RA. DNA vaccines: immunology, application, and optimization. Annu Rev Immunol. 2000;18:927-74.

3. Yagnik B, Padh H, Desai P. Construction of a new shuttle vector for DNA delivery into mammalian cells using non-invasive Lactococcus lactis. Microbes Infect. 2016;18:237-44.

4. Guimarães VD, Gabriel JE, Lefèvre F, Cabanes D, Gruss A, Cossart $\mathrm{P}$, et al. Internalin-expressing Lactococcus lactis is able to invade small intestine of guinea pigs and deliver DNA into mammalian epithelial cells. Microbes Infect. 2005;7:836-44.

5. Yagnik B, Sharma D, Padh H, Desai P. Immunization with rLactococcus lactis expressing outer membrane protein A of Shigella dysenteriae type-1: evaluation of oral and intranasal route of administration. J Appl Microbiol. 2017;122:493-505.

6. Yagnik B, Patel S, Dave M, Sharma D, Padh H, Desai P. Factors affecting inducible expression of outer membrane protein $\mathrm{A}$ (OmpA) of Shigella dysenteriae type-1 in Lactococcus lactis using Nisin inducible controlled expression (NICE). Indian J Microbiol. 2016;56:80-7.

7. Yagnik B, Sharma D, Padh H, Desai P. Dual recombinant Lactococcus lactis for enhanced delivery of DNA vaccine reporter plasmid pPERDBY. Microbiol Immunol. 2017;61:123-9.

8. Bradford MM. A rapid and sensitive method for the quantitation of microgram quantities of protein utilizing the principle of protein-dye binding. Anal Biochem. 1976;72:248-54.

9. Sharma D, Yagnik B, Baksi R, Desai N, Padh H, Desai P. Shigellosis murine model established by intraperitoneal and intranasal route of administration: a comparative comprehension overview. Microbes Infect. 2016;19:47-54.

10. Mitragotri S. Immunization without needles. Nat Rev Immunol. 2005;5:905-16.

11. Alert N. Preventing needlestick injuries in health care settings. Columbia Parkway Cincinnati. 2000-108; 1999.

12. Kermode M. Unsafe injections in low-income country health settings: need for injection safety promotion to prevent the spread of blood-borne viruses. Health Promot Int. 2004;19:95-103.

13. World Health Organization. State of the world's vaccines and immunization. Washington DC 1996. p. 1-212.

14. Detmer A, Glenting J. Live bacterial vaccines - a review and identification of potential hazards Microb Cell Fact. 2006;5:23.

15. Mercenier A,Müller-Alouf H,Grangette C, Lactic acid bacteria as live vaccines. Curr Issues Mol Biol. 2000;2:17-25.

16. Guimarães V, Innocentin S, Chatel J-M, Lefèvre F, Langella P, Azevedo V, et al. A new plasmid vector for DNA delivery using Lactococci. Genet Vaccin Ther. 2009;7:4.

17. Guimarães VD, Innocentin S, Lefèvre F, Azevedo V, Wal J-M, Langella $\mathrm{P}$, et al. Use of native lactococci as vehicles for delivery of DNA into mammalian epithelial cells. Appl Environ Microbiol. 2006;72:7091-7.

18. Innocentin S, Guimarães V, Miyoshi A, Azevedo V, Langella P, Chatel J-M, et al. Lactococcus lactis expressing either Staphylococcus aureus fibronectin-binding protein A or Listeria monocytogenes internalin A can efficiently internalize and deliver DNA in human epithelial cells. Appl Environ Microbiol. 2009; 75:4870-8.

19. de Azevedo M, Karczewski J, Lefévre F, Azevedo V, Miyoshi A, Wells JM, et al. In vitro and in vivo characterization of DNA delivery using recombinant Lactococcus lactis expressing a mutated form of L. monocytogenes Internalin A. BMC Microbiol. 2012;12:299.

20. Ansari AM, Ahmed AK, Matsangos AE, Lay F, Born LJ, Marti G, et al. Cellular GFP toxicity and immunogenicity: potential confounders in in vivo cell tracking experiments. Stem Cell Rev Rep. 2016;12:553-9.

21. Mancha-Agresti P, Drumond MM, Carmo FLR, do, Santos MM, Santos JSC, dos, Venanzi F, et al. A new broad range plasmid for
DNA delivery in eukaryotic cells using lactic acid bacteria: in vitro and in vivo assays. Mol Ther Methods Clin Dev. 2017;4:83-91.

22. Stripecke R, Del M, Villacres C, Skelton D, Satake N, Halene S, et al. Immune response to green fluorescent protein: implications for gene therapy. Gene Ther. 1999;6:1305-12.

23. Skelton D, Satake N, Kohn DB. The enhanced green fluorescent protein (eGFP) is minimally immunogenic in C57BL/6 mice. Gene Ther. 2001;8:1813-4.

24. Rosenzweig M, Connole M, Glickman R, Yue SP, Noren B, DeMaria $\mathrm{M}$, et al. Induction of cytotoxic $\mathrm{T}$ lymphocyte and antibody responses to enhanced green fluorescent protein following transplantation of transduced CD34(+) hematopoietic cells. Blood. 2001;97:1951-9.

25. Schubbert R, Hohlweg U, Renz D, Doerfler W. On the fate of orally ingested foreign DNA in mice: chromosomal association and placental transmission to the fetus. Mol Gen Genet. 1998;259:569-76.

26. Hohlweg U, Doerfler W. On the fate of plant or other foreign genes upon the uptake in food or after intramuscular injection in mice. Mol Genet Genom. 2001;265:225-33.

27. Palka-Santini M, Schwarz-Herzke B, Hösel M, Renz D, Auerochs $\mathrm{S}$, Brondke $\mathrm{H}$, et al. The gastrointestinal tract as the portal of entry for foreign macromolecules: fate of DNA and proteins. Mol Genet Genom. 2003;270:201-15.

28. Chatel J-M, Pothelune L, Ah-Leung S, Corthier G, Wal J-M, Langella $\mathrm{P}$. In vivo transfer of plasmid from food-grade transiting lactococci to murine epithelial cells. Gene Ther. 2008; 15:1184-90.

29. Hanahan D. Studies on transformation of Escherichia coli with plasmids. J Mol Biol. 1983;166:557-80.

30. Kimoto H, Kurisaki J, Tsuji NM, Ohmomo S, Okamoto T. Lactococci as probiotic strains: adhesion to human enterocyte-like Caco- 2 cells and tolerance to low $\mathrm{pH}$ and bile. Lett Appl Microbiol. 1999;29:313-6.

31. Kraehenbuhl JP, Neutra MR. Epithelial M cells: differentiation and function. Annu Rev Cell Dev Biol. 2000;16:301-32.

32. Seipp R. Mucosal immunity and vaccines. Sci Creative Quarterly. 2003; 8:1-8.

33. Mohamadzadeh M, Olson S, Kalina WV, Ruthel G, Demmin GL, Warfield KL, et al. Lactobacilli activate human dendritic cells that skew T cells toward T helper 1 polarization. Proc Natl Acad Sci USA. 2005;102:2880-5.

34. Borrego B, Fernandez-Pacheco P, Ganges L, Domenech N, Fernandez-Borges N, Sobrino F, et al. DNA vaccines expressing $\mathrm{B}$ and $\mathrm{T}$ cell epitopes can protect mice from FMDV infection in the absence of specific humoral responses. Vaccine. 2006; 24:3889-99.

35. Foligne B, Zoumpopoulou G, Dewulf J, Ben Younes A, Chareyre F, Sirard J-C, et al. A key role of dendritic cells in probiotic functionality. PLoS ONE. 2007;2:e313.

36. King DFL, McKay PF, Mann JFS, Jones CB, Shattock RJ. Plasmid DNA vaccine co-immunisation modulates cellular and humoral immune responses induced by intranasal inoculation in mice. PLoS ONE. 2015;10:e141557.

37. Zhao K, Rong G, Hao Y, Yu L, Kang H, Wang X, et al. IgA response and protection following nasal vaccination of chickens with Newcastle disease virus DNA vaccine nanoencapsulated with Ag@SiO2 hollow nanoparticles. Sci Rep. 2016;6:25720.

38. Seegers JFML. Lactobacilli as live vaccine delivery vectors: progress and prospects. Trends Biotechnol. 2002;20:508-15.

39. Mercenier A, Pavan S, Pot B. Probiotics as biotherapeutic agents: present knowledge and future prospects. Curr Pharm Des. 2003;9:175-91.

40. Ahmed B, Loos M, Vanrompay D, Cox E. Oral immunization with Lactococcus lactis-expressing EspB induces protective 
immune responses against Escherichia coli $0157: \mathrm{H} 7$ in a murine model of colonization. Vaccine. 2014;32:3909-16.

41. Masood MI, Qadir MI, Shirazi JH, Khan IU. Beneficial effects of lactic acid bacteria on human beings. Crit Rev Microbiol. 2011;37:91-8.

42. Yam KK, Pouliot P, N'diaye MM, Fournier S, Olivier M, Cousineau B. Innate inflammatory responses to the Gram-positive bacterium Lactococcus lactis. Vaccine. 2008;26:2689-99.

43. Kim S-H, Seo K-W, Kim J, Lee K-Y, Jang Y-S. The M celltargeting ligand promotes antigen delivery and induces antigenspecific immune responses in mucosal vaccination. J Immunol. 2010;185:5787-95.
44. Sambrook J, Russell DW. Molecular cloning: a laboratory manual. 3rd edn. New York, USA: Cold Spring Harbor Laboratory Press; 2001.

45. Hongying F, Xianbo W, Fang Y, Yang B, Beiguo L. Oral immunization with recombinant Lactobacillus acidophilus expressing the adhesin Hp0410 of Helicobacter pylori induces mucosal and systemic immune responses. Clin Vaccin Immunol. 2014;21:126-32.

46. Pore D, Mahata N, Pal A, Chakrabarti MK. Outer membrane protein A (OmpA) of Shigella flexneri 2a, induces protective immune response in a mouse model. PLoS ONE. 2011;6:e22663. 